\title{
Considerações sobre a aplicação da teoria da perda de uma chance na responsabilidade civil do médico
}

\section{Considerations on the implementation of the theory of loss of chance on doctor's civil responsability}

\author{
Eduardo Nunes de Souza*
}

\section{Resumo}

A teoria da perda de uma chance, de aplicação excepcional, não se coaduna com a responsabilidade civil médica, na medida em que sua verificação é muito mais complexa nas hipóteses em que ocorre um dano concreto (como acontece, em regra, nos casos de responsabilidade do médico), e levando-se em conta que sua aplicação nessa seara muito se aproxima da lógica do erro médico (de todo indesejável, já que obscurece a importância da aferição da culpa profissional por meio de um juízo de valor feito a posteriori sobre o dano sofrido pelo paciente).

Palavras-chave: Perda de uma chance. Responsabilidade civil médica. Erro médico.

\section{Abstract}

The loss of a chance theory, which must be applied only exceptionally, is not suitable for medical civil liability, as its verification is much more complex in the hypothesis in which a concrete damage occurs (such as, in principle, the cases of medical liability), and taking into consideration that its application in this field proves to be very close of the one of medical malpractice (which is not desirable, since it clouds the importance of the verification of professional fault through a judgement on the damage that the patient has suffered).

Keywords: Loss of a chance. Medical civil liability. Medical malpractice.

Doutorando e mestre em Direito Civil pela Universidade do Estado do Rio de Janeiro. Professor contratado dos cursos de Graduação e Pós-Graduação Lato Sensu da Faculdade de Direito da Universidade do Estado do Rio de Janeiro. Assessor jurídico junto ao Tribunal de Justiça do Rio de Janeiro. Rio de Janeiro - RJ - Brasil. Email: ens@gmail.com 


\section{Introdução}

Se a responsabilidade civil do médico é de natureza subjetiva, sua análise depende, fundamentalmente, de como a culpa se manifesta na produção de danos no exercício da medicina. Não se trata, porém, de hipótese essencialmente distinta dos demais casos de responsabilidade civil subjetiva: a prática culposa da medicina não difere, em natureza ou efeitos, de qualquer outra conduta culposa ensejadora de dano ressarcível (AGUIAR JÚNIOR, 2000, p. 145). De fato, embora parte da doutrina fizesse distinção entre culpa ordinária e culpa profissional (esta última associada a condutas exclusivas de determinado ofício), a classificação acabou superada, diante de sua irrelevância para a disciplina da responsabilidade do médico (PEREIRA, 2011, p. 204).

A culpa na responsabilidade civil do profissional de saúde costuma ser materializada na figura do denominado erro médico. Trata-se de acepção bastante ampla do termo "erro", aqui compreendido como "uma falha no exercício da profissão, do que advém um mau resultado ou um resultado adverso, efetivando-se através da ação ou omissão de um profissional" (GIOSTRI, 2005, p. 125). Embora onipresente nas obras que se dedicam ao assunto, a expressão "erro médico" oferece ao menos uma incerteza ao estudioso: justamente quanto à sua natureza. Trata-se de expressão leiga ${ }^{1}$, mas não são raras as ocasiões em que se faz alusão ao erro médico como se se tratasse de um requisito da responsabilização civil do médico, embora não se trate, a rigor, de qualquer dos elementos necessários à configuração da responsabilidade civil subjetiva (dano, nexo causal e conduta culposa) ${ }^{2}$.

O chamado erro médico constitui juízo de valor a posteriori sobre a conduta profissional, promovendo uma comparação entre o procedimento adotado e aquele que, em tese, teria evitado o dano

Expressão que não se confunde, evidentemente, com o defeito do negócio jurídico também denominado "erro", disciplinado pelos arts. 138 e ss. do Código Civil.

2 Para um maior desenvolvimento desta crítica, permita-se remeter a Souza (2015, p. 104-113). Cf., ainda, na doutrina francesa, Penneau (1973, passim). 
já conhecido. Em outras palavras, o juízo valorativo do erro não está propriamente interessado na maior ou menor diligência adotada pelo médico, não indaga se ele desejava ou não produzir o dano, não identifica se a legítima confiança do paciente na conduta do médico foi violada. A noção de erro avalia apenas se a conduta médica adotada diferiu de outra conduta que, analisada em abstrato, poderia não ter causado o dano ${ }^{3}$. O médico absolutamente diligente que, diante de dois tratamentos igualmente cabíveis (segundo o mais apurado conhecimento científico) para determinado quadro clínico, prescreve um deles e não consegue curar o enfermo, na acepção corrente do termo, errou tanto quanto aquele que prescreve um terceiro tratamento, totalmente inapropriado ${ }^{4}$.

Como se percebe, o problema em se confundir erro e culpa reside na conclusão lógica decorrente da equiparação: se o erro equivale à culpa, sempre que a conduta médica conduzir a um dano e for possível cogitar outro procedimento que, hipoteticamente, não produziria o mesmo prejuízo, restaria configurada a responsabilidade do médico. Dito de outro modo, equiparar o erro à culpa significa promover uma objetivação velada da responsabilidade do médico. Além disso, a expressão "erro médico" apresenta um último inconveniente: revela-se muito próxima da concepção clássica de culpa ${ }^{5}$, dita culpa psicológica, associada à violação de dever específico preexistente, na formulação clássica de Planiol, e vinculada à consciência do procedimento e à previsibilidade do resultado (PEREIRA, 2011, p. 75-77).

$3 \quad$ Na síntese de Ruy Rosado de Aguiar Júnior (2000, p. 145), com base na jurisprudência da Corte de Cassação francesa: "a culpa supõe uma falta de diligência ou de prudência em relação ao que era esperável de um bom profissional escolhido como padrão; o erro é a falha do homem normal, consequência inelutável da falibilidade humana".

4 Adverte Marcelo Benacchio (2009, p. 336): "as consequências danosas oriundas do próprio tratamento preconizado pela ciência médica, apesar da causalidade com a atuação do médico, não podem ser compreendidas como erro médico em virtude de serem decorrências das vicissitudes do próprio corpo humano e dos limites da ciência que persegue seu tratamento [...]".

5 Adverte Maria Celina Bodin de Moraes (2003, p. 215): "especialmente devido à reconhecida dificuldade em diferenciar erro e culpa, mais útil ainda se torna o aproximar-se da concepção normativa em sentido estrito, isto é, defender a relatividade da culpa (rectius, do erro), inclusive com relação a cada uma das especialidades médicas". 
O direito civil contemporâneo, ao contrário, caminha em direção à adoção de parâmetros objetivos de valoração dos fatos jurídicos, o que tem ocasionado, no que concerne à disciplina da responsabilidade civil subjetiva, a substituição da concepção psicológica da culpa por uma segunda noção, denominada culpa normativa, baseada no descumprimento da máxima do neminem laedere. Nessa acepção, "a culpa seria um desvio do modelo de conduta representado pela boa-fé e pela diligência média, isto é, ação ou omissão que não teria sido praticada por pessoa prudente, diligente e cuidadosa, em iguais circunstâncias" (BODIN DE MORAES, 2003, p. 211). Com a noção normativa da culpa, valorizam-se os componentes objetivos do comportamento juridicamente merecedor de tutela, de tal modo que seu descumprimento se torna o fundamento de imputação da responsabilidade ${ }^{6}$, afastando-se o exame - ficcional e, portanto, inconveniente em si mesmo - de qualquer elemento subjetivo vinculado à consciência e à possível previsibilidade em relação ao resultado danoso.

No caso da responsabilidade civil do médico, a noção de culpa normativa se relaciona com a adequação do procedimento adotado à luz do estado atual da ciência e com a construção de uma relação médicopaciente baseada na confiança recíproca e na troca de informações entre ambos $^{7}$. A utilidade dessa concepção de culpa como descumprimento de padrões de conduta mostra-se relevante em casos como aqueles em que se costuma invocar a teoria da perda de uma chance para responsabilizar o médico pela suposta privação da oportunidade de cura que determinado tratamento por ele ministrado causaria ao paciente. Trata-se de mais uma construção teórica que acaba por obscurecer, na

$6 \quad$ Na clássica página de Stefano Rodotà (1967, p. 173-174): "La violazione del limite della solidarietà, implicita nell'esserci verificato un danno ingiusto, esige [...] una qualificazione in direzione soggettiva, perchè si possa far luogo alla imputazione della responsabilità a titolo di colpa [...]. Questa qualificazione è possibile in quanto il limite della solidarietà si presenta pure come misura dell'agire, standard operante sempre che un contatto sociale specifica in concreto l'esigenza di apprezzare le componenti obiettive del comportamento".

7 Tal conteúdo atribuído ao padrão de conduta médica diligente é desenvolvido com maior detalhe em Souza (2015, p. 183-205). 
prática, o exame da culpa médica, da mesma forma como aconteceu com o erro médico.

\section{Perda de uma chance clássica e perda de uma chance de cura}

A teoria da perda de uma chance tem, como boa parte das categorias conhecidas em matéria de responsabilidade civil, sua origem atribuída ao direito francês ${ }^{8}$. A perte d'une chance representa a hipótese em que a conduta de determinado agente faz desaparecer para o lesado a probabilidade de um evento que poderia lhe gerar um benefício futuro ${ }^{9}$. Costuma-se afirmar que a reparação pela perda de uma chance "repousa em uma probabilidade e uma certeza; que a chance seria realizada, e que a vantagem perdida resultaria em prejuízo" (PEREIRA, 2011, p. 61). Por essa razão, exige-se que se trate de uma chance séria e real, cuja perda constitua um prejuízo material ou imaterial concreto ${ }^{10}$ (CAVALIERI FILHO, 2005, p. 75).

Na prática jurisprudencial brasileira, tornaram-se célebres alguns casos de aplicação da teoria da perda de uma chance, como aquele, julgado pelo STJ, em que se apreciou a conduta de determinada emissora de televisão que, em um programa de perguntas e respostas, propôs à participante, candidata a ganhar um milhão de reais, uma pergunta (justamente a pergunta milionária) para a qual nenhuma das

Sobre os primeiros precedentes versando sobre a perda de uma chance, v. Silva (2009, p. 1011).

9 Esta é a definição de Sergio Cavalieri Filho (2005, p. 75), que remata: "Deve-se, pois, entender por chance a probabilidade de se obter um lucro ou de se evitar uma perda".

10 A respeito, comentam Carlos Nelson Konder e Thamis Dalsenter (2013, p. 488): "Se a teoria [da perda de uma chance] tem aplicação quando não é possível provar cabalmente o nexo causal entre a ação ou omissão e o resultado danoso e, além disso, se a sua fundamentação teórica relaciona-se com uma apreciação em abstrato, baseada na probabilidade, é necessário, para se assegurar um patamar mínimo e inafastável de segurança jurídica, que tal probabilidade seja real, ou seja, que se possa verificar que a chance perdida tenha representatividade". No mesmo sentido, v. Savi (2006, p. 43). 
quatro alternativas de resposta estava correta ${ }^{11}$. Desistindo de responder à pergunta, a participante auferiu meio milhão de reais, posteriormente ajuizando ação de perdas e danos em face da emissora. Chegando o caso ao STJ, a Corte entendeu ser cabível atribuir à emissora o dever de reparar a participante no valor de $25 \%$ do outro meio milhão que poderia ter ganhado caso uma das alternativas estivesse correta (porcentagem que representaria justamente sua chance de acerto em uma pergunta com uma alternativa certa em quatro).

Este e outros precedentes ${ }^{12}$ têm sido reunidos por parte da doutrina sob a denominação de perda de uma chance clássica ${ }^{13}$. A nota característica dessa teoria clássica reside no fato de a chance perdida corresponder a um benefício para o lesado; em outras palavras, indeniza-se a vítima por se lhe ter suprimido a oportunidade de um ganho ou benefício. O dano, vale repetir, consiste na subtração da

11 STJ, REsp. 788.459/BA, 4a. T., Rel. Min. Fernando Gonçalves, julg. 8.11.2005: "Recurso especial. Indenização. Impropriedade de pergunta formulada em programa de televisão. Perda da oportunidade. 1. O questionamento, em programa de perguntas e respostas, pela televisão, sem viabilidade lógica, uma vez que a Constituição Federal não indica percentual relativo às terras reservadas aos índios, acarreta, como decidido pelas instâncias ordinárias, a impossibilidade da prestação por culpa do devedor, impondo o dever de ressarcir o participante pelo que razoavelmente haja deixado de lucrar, pela perda da oportunidade. 2. Recurso conhecido e, em parte, provido".

12 Dentre outros exemplos de aplicação da teoria, v. STJ, REsp. 821.004/MG, $3^{\text {a }}$ T., Rel. Min. Sidnei Beneti, julg. 19.8.2010: "Aplica-se a teoria da perda de uma chance ao caso de candidato a Vereador que deixa de ser eleito por reduzida diferença de oito votos após atingido por notícia falsa publicada por jornal, resultando, por isso, a obrigação de indenizar"; STJ, EDcl. no REsp. 1.321.606/MS, 4 ${ }^{\mathrm{a}}$ T., Rel. Min. Antonio Carlos Ferreira, julg. 23.4.2013: "Responsabilidade civil do advogado, diante de conduta omissiva e culposa, pela impetração de mandado de segurança fora do prazo e sem instruí-lo com os documentos necessários, frustrando a possibilidade da cliente, aprovada em concurso público, de ser nomeada ao cargo pretendido. Aplicação da teoria da 'perda de uma chance'".

13 A distinção entre a perda de uma chance na seara médica e todas as outras hipóteses de perda de uma chance (ditas "perda de uma chance clássica") é adotada pela maior parte da doutrina francesa, capitaneada por René Savatier, que distingue entre "casos nos quais o fato alegado aumentou as chances de realização de um dano que se fato foi produzido" e "casos em que o fato alegado diminuiu as chances de realização de um evento favorável que, efetivamente, não ocorreu" (Traité de la responsabilité civile en droit français. t II, cit., p. 8-10 - n. 460 e 461). No direito brasileiro, cf. Noronha (2010, p. 70). 
própria oportunidade desse ganho, independentemente de qualquer consideração quanto à vantagem em si que se deixou de auferir ${ }^{14}$. A consideração de que a simples oportunidade constituiria um bem jurídico passível de lesão e, consequentemente, de reparação autônoma em relação ao benefício ao qual essa oportunidade poderia conduzir é a base teórica para a compatibilização da teoria da perda de uma chance, com a vedação da reparação ao dano hipotético ${ }^{15}$. Não seria a vantagem abstratamente auferível que se buscaria repor, mas a simples chance de obtê-la, pois se entende que essa chance existia concretamente na esfera jurídica do lesado ${ }^{16}$. A dificuldade na aceitação da perda de uma

14 Por se considerar que esta oportunidade já integrava o patrimônio do lesado, parte da doutrina afirma que a perda de uma chance se aproxima do dano emergente, e não do lucro cessante, como poderia parecer à primeira vista. A respeito, v. Carlos Nelson Konder e Thamis Dalsenter, (2013, p. 489). A respeito, cf. também Savi (2006, p. 102): "em determinados casos, a chance ou oportunidade poderá ser considerada um bem integrante do patrimônio da vítima, uma entidade econômica e juridicamente valorável, cuja perda produz um dano, na maioria das vezes atual, o qual deverá ser indenizado sempre que a sua existência seja provada, ainda que segundo um cálculo de probabilidade ou por presunção. A perda de chance, como visto, ao contrário do afirmado por alguns doutrinadores, deve ser considerada em nosso ordenamento uma subespécie de dano emergente" (Responsabilidade civil por perda de uma chance, cit., p. 102).

15 Conforme leciona Caio Mário da Silva Pereira (2011, p. 58-59): "O outro requisito do dano é que seja certo. Não se compadece com o pedido de reparação um prejuízo meramente eventual. [...] Normalmente, a apuração da certeza vem ligada à atualidade. O que se exclui de reparação é o dano meramente hipotético, eventual ou conjuntural, isto é, aquele que pode não vir a concretizarse".

16 A análise em abstrato de causas aptas à produção do dano remete à teoria da causalidade adequada, ao passo que, como se sabe, o ordenamento brasileiro adota a teoria da causalidade direta e imediata, conforme aduz Gustavo Tepedino (2011, p. 110-111): "apenas se consideram causas aquelas vinculadas ao dano direta e imediatamente, sem a interferência de qualquer causa sucessiva. Nessa perspectiva, estaria excluída a ressarcibilidade do chamado dano remoto ou dano por ricochete. No entanto, o ressarcimento por danos reflexos era vastamente reconhecido pela jurisprudência, em especial para condenar também à prestação de alimentos o responsável por homicídio cuja vítima deixara dependentes, hipóteses que restou positivada no art. 948, II, do Código Civil [...]. Diante da insuficiência dessa construção doutrinária para explicar a aludida admissibilidade, pelo texto legal, do dano indireto ou remoto, formulou-se construção evolutiva da teoria da relação causal imediata, denominada de subteoria da necessariedade da causa [...]. Em termos práticos, os tribunais brasileiros costumam invocar a causalidade adequada, investigando, contudo, em concreto, qual a causa mais adequada - ou seja, necessária - para a produção do dano". 
chance reside justamente na falta de necessariedade entre o dano e a conduta ${ }^{17}$.

A diferença na aplicação da teoria da perda de uma chance ao caso do médico está no fato de que a chance perdida não conduziria à obtenção de um benefício, mas sim ao possível impedimento de um malefício. Em outros termos, enquanto na maior parte dos casos de perda de uma chance a parte lesada perde a oportunidade de ganhar algo, nos casos relacionados à prática da medicina, a vítima sofreria um dano que já estava em curso e teria perdido a chance de evitá-lo. ${ }^{18}$ A hipótese, como se percebe, é bem mais complexa, já que, segundo parte da doutrina, a situação fática ofereceria dois danos distintos a serem disciplinados: o primeiro, que já estava em vias de acontecer e não se pôde evitar, e o segundo, da oportunidade perdida de se evitar o primeiro dano.

Assim ocorreu, por exemplo, em caso julgado pelo STJ, no qual uma paciente que sofria de câncer de mama foi submetida a determinado tratamento por seu médico, vindo posteriormente a falecer pelo desenvolvimento da doença. Vislumbraram-se, no caso, dois danos: o primeiro, mais evidente, do próprio óbito; e o segundo, da

17 Aduz Rafael Peteffi da Silva (2009, p. 56): "nos casos de perda de uma chance, a falha do agente, ou a falha médica ou do advogado, não constitui uma conditio sine qua para o aparecimento do dano. A vantagem esperada pela vítima pode ser totalmente perdida, exclusivamente devido a outras causas, como o desenvolvimento da doença ou a jurisprudência vacilante em determinada matéria".

18 Conforme se extrai do inteiro teor de decisão do STJ relatada pela Min. Nancy Andrighi: "Nas hipóteses de Perda da Chance Clássica, há sempre certeza quanto à autoria do fato que frustrou a oportunidade, e incerteza quanto à existência ou à extensão dos danos decorrentes desse fato. [...] Por isso a indenização é fixada mediante uma redução percentual do ganho que, em princípio, poderia ser auferido pelo prejudicado. Assim, se este tinha $60 \%$ de chances de sucesso caso tivesse aproveitado a oportunidade perdida, a indenização será fixada em $60 \%$ sobre o valor total dos hipotéticos lucros cessantes. Na hipótese dos autos, contudo, a oportunidade perdida é de um tratamento de saúde que poderia interromper um processo danoso em curso, que levou a paciente à morte. Aqui, a extensão do dano já está definida, e o que resta saber é se esse dano teve como concausa a conduta do réu. $\mathrm{A}$ incerteza, portanto, não está na consequência. Por isso ganha relevo a alegação da ausência de nexo causal. A conduta do médico não provocou a doença que levou ao óbito mas, mantidas as conclusões do acórdão quanto às provas dos autos, apenas frustrou a oportunidade de uma cura incerta" (BRASII. STJ. REsp. 1.254.141/PR, $3^{\mathrm{a}}$ T., Rel. Min. Nancy Andrighi, julg. 4.12.2012). 
chance perdida pela paciente de, ao se submeter a tratamento diverso, não desenvolver a metástase. No acórdão, aplicou-se amplamente a teoria da perda de uma chance para se justificar o dever do médico de indenizar a família da vítima, conforme demonstra a ementa da decisão:

DIREITO CIVIL. CÂNCER. TRATAMENTO INADEQUADO. REDUÇÃO DAS POSSIBILIDADES DE CURA. ÓBITO. IMPUTAÇÃO DE CULPA AO MÉDICO. POSSIBILIDADE DE APLICAÇÃO DA TEORIA DA RESPONSABILIDADE CIVIL PELA PERDA DE UMA CHANCE. REDUÇÃO PROPORCIONAL DA INDENIZAÇÃO. RECURSO ESPECIAL PARCIALMENTE PROVIDO. 1. O STJ vem enfrentando diversas hipóteses de responsabilidade civil pela perda de uma chance em sua versão tradicional, na qual o agente frustra à vítima uma oportunidade de ganho. Nessas situações, há certeza quanto ao causador do dano e incerteza quanto à respectiva extensão, o que torna aplicável o critério de ponderação característico da referida teoria para a fixação do montante da indenização a ser fixada. Precedentes. 2. Nas hipóteses em que se discute erro médico, a incerteza não está no dano experimentado, notadamente nas situações em que a vítima vem a óbito. $A$ incerteza está na participação do médico nesse resultado, à medida que, em princípio, o dano é causado por força da doença, e não pela falha de tratamento. 3 . Conquanto seja viva a controvérsia, sobretudo no direito francês, acerca da aplicabilidade da teoria da responsabilidade civil pela perda de uma chance nas situações de erro médico, é forçoso reconhecer sua aplicabilidade. Basta, nesse sentido, notar que a chance, em si, pode ser considerada um bem autônomo, cuja violação pode dar lugar à indenização de seu equivalente econômico, a exemplo do que se defende no direito americano. Prescinde-se, assim, da difícil sustentação da teoria da causalidade proporcional. 4 . Admitida a indenização pela chance perdida, o valor do bem deve ser calculado em uma proporção sobre o prejuízo final experimentado pela vítima. A chance, contudo, jamais pode alcançar o valor do bem perdido. É necessária uma redução 
proporcional. 5. Recurso especial conhecido e provido em parte, para o fim de reduzir a indenização fixada ${ }^{19}$.

Como se percebe, o óbito da paciente decorre do desenvolvimento de uma cadeia causal iniciada com o próprio surgimento do câncer, antes de qualquer intervenção médica. Justamente por isso, o médico, recorrendo da decisão condenatória, alegou ausência de nexo causal entre a sua conduta e o dano: a morte teria sido causada pela doença, e não por sua intervenção ${ }^{20}$. De fato, para que o médico pudesse ser responsabilizado, seria necessário reconhecer que sua intervenção causou um dano autônomo, como sustentou a decisão do STJ, ou que a atuação do profissional ingressou, como concausa, na cadeia de causalidade do evento danoso, iniciada por uma causa fortuita (o surgimento da própria doença).

\section{Crítica à aplicação da teoria da perda de uma chance à responsabilidade civil do médico}

Boa parte da doutrina que se dedica ao tema associa a perda de uma chance a uma questão de causalidade. Com efeito, ao se afirmar que a conduta médica privou o paciente da chance da cura, o que se afirma, na verdade, é que a conduta médica manteve relação causal com o dano produzido, tornando-se concausa para o surgimento deste. Mesmo considerando-se que o dano decorrente da perda de uma chance seria autônomo em relação ao dano-morte, o problema da aplicação dessa teoria ao caso da medicina está no fato de que nem o juízo de causalidade nem a identificação de um suposto dano autônomo permitem, isoladamente, fazer qualquer consideração quanto à culpa do médico, elemento fundamental para a sua responsabilização.

19 STJ, REsp. 1.254.141/PR, 3a T., Rel. Min. Nancy Andrighi, julg. 4.12.2012.

20 Relata o inteiro teor do acórdão em comento: "O recorrente afirma que sua condenação não poderia ter sido fundamentada exclusivamente na teoria da Perda da Chance porquanto restaria ausente o indispensável nexo causal [...]". 
Em outros termos, aproxima-se muito a responsabilidade pela perda de uma chance da lógica do já criticado "erro médico": partese de um juízo a posteriori, quando já se conhece o dano produzido ${ }^{21}$ (em geral, a morte ou o agravamento da enfermidade) e se verifica, em abstrato, a existência de outro tratamento ou procedimento que poderia não produzir o mesmo resultado ${ }^{22}$. Nas mesmas circunstâncias em que se afirma usualmente que o médico "errou" (vale repetir, tendo-se em conta a produção de um dano pela conduta médica e a comparação dessa conduta, em abstrato, com outra possibilidade de tratamento que talvez não causasse o mesmo resultado), poder-se-ia também afirmar que o médico causou ao paciente a "perda de uma chance de cura". Faz-se aqui a aproximação entre ambas as expressões ("erro" e "perda de uma chance"), apesar da evidente desvinculação entre elas, apenas para salientar que nenhuma das duas faz qualquer consideração quanto à culpa do profissional, constituindo, em vez disso, um drástico reforço semântico para a responsabilização do médico.

Ora, que o tratamento oferecido pelo médico ao paciente ingressou, nesses casos, na cadeia causal que produziu o dano já se sabe (pois, do contrário, o paciente teria sido curado pela intervenção médica, ou esta última se provaria absolutamente inócua, não agravando nem melhorando seu estado de saúde - e então não se colocaria a questão

21 Segundo Rafael Peteffi da Silva (2009, p. 85), esta é uma crítica difundida na doutrina francesa; os autores contrários à aplicação da teoria da perda de uma chance na seara médica "fundam suas críticas na impossibilidade de se perquirirem as chances perdidas após o término do processo aleatório. Assim, a análise das chances perdidas não será mais uma suposição em direção ao futuro e a um evento aleatório cujo resultado nunca se saberá, mas uma análise de fatos já ocorridos, pois é absolutamente certo que o paciente restou inválido ou morto".

22 Afinal, se apenas as chances reais e sérias são indenizáveis quando perdidas, então é necessário que houvesse confirmadamente uma possibilidade de sobrevida do paciente, tivesse o médico adotado outra conduta qualquer. A aproximação com a lógica do erro médico é evidente, e tal aproximação é muitas vezes feita pela própria doutrina. Nas palavras de Anderson Schreiber (2013, p. 199): "se 'não há como fazer qualquer afirmação' de que 'o resultado morte poderia ter sido evitado', não há certeza quanto à existência da chance em si mesma. A mera hipótese de que o paciente tivesse uma chance de sobrevida não basta à responsabilização do médico. É preciso que haja, ao menos, a certeza de que, suprimido o erro médico, a chance de sobrevida existiria. Vale dizer: o erro médico deve ter privado o paciente de uma chance séria e real de permanecer vivo". 
da responsabilidade do profissional). A dúvida resta na imputabilidade do dano ao profissional - imputabilidade esta que, como se propôs ao longo deste estudo, necessariamente depende do elemento culposo ${ }^{23}$. Das duas, uma: ou bem o médico agiu com culpa - e, então, o dano pelo qual responderá será o próprio óbito ou agravamento da enfermidade do paciente, na proporção de sua participação, como concausa para esses danos, sem a necessidade de se invocar a figura de um dano novo decorrente da perda da chance ${ }^{24}$-, ou não agiu com culpa - e, nesse caso, não responderá pelo óbito (ou agravamento da doença) nem por um hipotético dano autônomo consubstanciado na perda da chance ${ }^{25}$.

Parte das decisões que sustentam a perda da chance de cura o faz durante o exame da culpa do médico, como se a existência de outro tratamento que, em abstrato, permitisse a cura (fator levado em conta para a perda da chance e, como já se viu, para o erro médico) estivesse intrinsecamente ligada à análise do cumprimento do procedimento adequado pelo médico (ponderação necessária para a identificação de sua culpa). Ocorre, porém, que, não raro, há mais de um procedimento adequado a seguir, nem sempre com probabilidades drasticamente distintas de eficácia. $O$ tratamento médico é um ato complexo composto por muitas escolhas, e a simples existência de uma alternativa que

23 Na perda de uma chance aplicada à prática da medicina, as chances são observadas no passado, e não em uma prospecção do futuro: "No caso do advogado que perde o prazo recursal, o respectivo recurso nem chega a ser conhecido, não sendo possível dizer se ele seria procedente ou não, visto que aleatório. No caso do médico, o processo que poderia ter sido aleatório já não é mais, pois se sabe com certeza qual o resultado: a morte ou a invalidez do paciente, isto é, a única dúvida que resta nesse caso é a relação de causalidade entre a falha do profissional e o dano final, assim como no caso da ponte que pode ter caído pela culpa do engenheiro" (SILVA, 2009, p. 87).

24 Em sentido contrário, Anderson Schreiber (2013, p. 200) responde à crítica de Savatier quanto ao risco de o julgador confundir a incerteza quanto à chance perdida com a sua própria incerteza quanto à causalidade afirmando que "o risco, de fato, existe, mas não justifica que se negue indenização por perda da chance na seara médica".

25 Assim propõem os autores que, na França, opõem-se à aplicação da teoria da perda de uma chance ao caso da prática médica. Novamente no relato de Rafael Peteffi da Silva (2009, p. 85), citando René Savatier, "cabe pesquisar se as chances de cura perdidas estão localizadas antes ou depois da consolidação do acidente. No primeiro caso, se estaria diante de uma causalidade clássica, do contrário, se estaria utilizando uma causalidade parcial para determinar o dano". 
poderia ter permitido a cura não autoriza, per se, concluir que houve descumprimento da diligência profissional devida (vale dizer, agir culposo por parte do médico $)^{26}$.

Se assim fosse, quase todos os procedimentos ou terapias ensejariam perdas de chances - chances de tratamentos menos demorados, mais eficazes, menos dolorosos, mais baratos ou quaisquer outras considerações que se possa fazer hipoteticamente sobre escolhas não adotadas para o tratamento de um paciente em concreto. Não se pode responsabilizar o médico pelas escolhas que necessariamente terá que deixar de fazer em seu exercício profissional, mas sim pelas escolhas que efetivamente faz, quando estas destoarem do procedimento que a própria medicina considera adequado. Assim, as melhores decisões sobre a perda de uma chance na seara médica não levam em consideração, de fato, a perda da oportunidade da cura, mas sim a aferição da culpa no procedimento médico - conduzindo a acertadas conclusões quanto à imputabilidade ou não dos danos concretamente produzidos ao profissional. Outras tantas, porém, lançam mão da figura da perda da chance como argumento definitivo para exigir do médico uma indenização, independentemente de seu agir culposo - já que, sem dúvida, ao médico sempre se poderá imputar o fato de ter deixado de fazer certas escolhas hipotéticas em prol de outras concretamente adotadas (sendo essa, afinal, a natureza de sua atividade).

Exemplo da primeira hipótese é a já aludida decisão do STJ a respeito da paciente que faleceu após o tratamento inadequado de um câncer de mama, na qual se procede a uma análise exemplar do procedimento médico, concluindo-se pela condenação do profissional em face de seu comportamento culposo, depreendido do laudo pericial:

26 O desprestígio da culpa na aplicação da teoria da perda de uma chance à seara médica já foi observado, inclusive, na doutrina da common law, a despeito das profundas diferenças da torts law em relação ao sistema romano-germânico de responsabilidade civil. llustrativamente: "Pure loss of chance does not require the plaintiff to prove to a preponderance of the evidence that the doctor's negligence caused the victim's death" (BUCKLER, 2009, p. 128). 
Analisando a prova dos autos, o TJ/PR concluiu que o procedimento adotado pelo réu não foi adequado porque, em primeiro lugar, a melhor decisão acerca da cirurgia a ser feita para tratamento de câncer de mama depende essencialmente do tamanho do tumor. Na hipótese dos autos, segundo se apurou na perícia, não era possível afirmar com certeza qual o tamanho do tumor que vitimava a paciente, de modo que a sua classificação deveria ter sido estabelecida, necessariamente, como de tamanho não definido. Para hipóteses de tumores de tamanho não definido, a comunidade médica, segundo se apurou na perícia, jamais recomenda a cirurgia de quadrantectomia, mas a mastectomia radical.

Em segundo lugar, ficou estabelecido que a recomendação de quimioterapia e a radioterapia feita pelo réu, antes e depois da cirurgia, não observou o protocolo mais adequado, segundo a literatura médica atualizada, sendo que 'na doença neoplásica a escolha do tratamento ideal se baseia em dados estatísticos mas, mesmo com o tratamento ideal, existem casos com evolução desfavorável. A diferença é que o Requerido optou por oferecer um tratamento em que a chance de êxito ficou diminuída' (fl. 1.087, e-STJ).

Em terceiro lugar, 'houve também culpa no acompanhamento pós-cirúrgico', uma vez que 'o réu deveria ter solicitado outros exames' (fl. 1.088, e-STJ), como cintilografia óssea, mamografia, ultrassonografia de abdômen, raios-x de tórax. O médico, contudo, não seguiu esse procedimento $[\ldots]^{27}$.

Diante da justa imputação ao médico do dever de indenizar nesse caso concreto, a questão que se põe diz respeito à necessidade de se recorrer à teoria da perda de uma chance. Comprovado o comportamento culposo do profissional, não seria suficiente imputar a ele o óbito da paciente, proporcionalmente à sua contribuição para a causação do dano? Os autores sustentam a perda de uma chance como um dano autônomo buscam justamente evitar as dificuldades de se lidar com

27 Trecho do voto da Min. Nancy Andrighi. 
os problema da concorrência de causas e, mais ainda, da causalidade parcial e da causalidade alternativa na atuação do médico ${ }^{28}$. Esbarram, contudo, em um novo problema de causalidade: o de vincular a conduta médica a outro dano, consistente na supressão da oportunidade de cura, cuja existência já é, por si só, controversa.

Compreendida a hipótese em concreto, por outro lado, não como dano autônomo, mas como uma questão de causalidade, não há tampouco a necessidade de se recorrer à teoria da perda de uma chance, bastando recorrer-se à ideia de concorrência de causas, que influenciarão na quantificação da reparação a ser imputada ao médico. Não se trata de questão simples (como se constata, em geral, em matéria de nexo de causalidade), havendo mesmo autores que sustentam que não deveria haver qualquer responsabilidade para o médico nas hipóteses em que a doença simplesmente segue seu curso natural, sem ser evitada ${ }^{29}$. Segundo esses autores, ou bem o médico,

28 Assevera Rafael Peteffi da Silva (2009, p. 76): "[...] grande parte da doutrina assevera que a teoria da responsabilidade pela perda de uma chance não necessita da noção de nexo de causalidade alternativa para ser validada. Apenas uma maior abertura conceitual em relação aos danos indenizáveis seria absolutamente suficiente para a aplicação da teoria da perda de uma chance nos diversos ordenamentos jurídicos. [...] A simples interrupção do processo aleatório no qual se encontrava a vítima seria suficiente para caracterizar um dano reparável: a perda de uma chance. As chances perdidas seriam passíveis de aferição pecuniária, exatamente como ocorreria com o roubo de um bilhete de loteria antes do resultado do sorteio". Idêntico raciocínio é esboçado no acórdão do STJ que ora se comenta: "A solução para esse impasse, contudo, está em notar que a responsabilidade civil pela perda da chance não atua, nem mesmo na seara médica, no campo da mitigação do nexo causal. A perda da chance, em verdade, consubstancia uma modalidade autônoma de indenização, passível de ser invocada nas hipóteses em que não se puder apurar a responsabilidade direta do agente pelo dano final. Nessas situações, o agente não responde pelo resultado para o qual sua conduta pode ter contribuído, mas apenas pela chance de que ele privou a paciente. Com isso, resolve-se, de maneira eficiente, toda a perplexidade que a apuração do nexo causal pode suscitar".

29 Trata-se de posicionamento dos autores que entreveem na perda de uma chance a tentativa de responsabilizar parcialmente o profissional quando não há certeza quanto à causalidade. Conforme relata Anderson Schreiber (2013, p. 199-200), "Não faltam na doutrina críticas à aplicação da teoria da perda da chance no campo da responsabilidade médica. Argumenta-se que, em um terreno onde é quase impossível determinar se a morte do paciente adveio de efeitos da terapia empregada pelo médico (corretamente ou não) ou do simples desenvolvimento da doença, a responsabilização do profissional pela perda da chance de sobrevivência acabaria funcionando como uma solução salomônica, em que o juiz condenaria o médico, mas não pelo valor integral do dano". 
agindo culposamente, causou o dano e responde integralmente por ele, ou bem não poderá responder pelo resultado danoso, sob pena de se transformar a teoria da perda de uma chance, no dizer de Savatier, no "paraíso do juiz indeciso" 30 . De todo modo, a inserção de uma nova figura jurídica - a perda de uma chance - na questão (sobretudo se aplicada, de modo geral, às hipóteses de chance de obter um benefício, e não de oportunidade de evitar um dano) não contribui para simplificar o problema.

De fato, na seara médica, a aplicação da teoria da perda de uma chance parece relacionar-se com a necessidade, por parte da jurisprudência, de imputar ao profissional da medicina não apenas o dever de reparar, mas também uma ameaça preventiva. Trata-se, em outros termos, do chamado caráter punitivo, pedagógico ou exemplar da responsabilidade civil, amplamente difundido em nossos tribunais, mas repelido pela melhor doutrina, que reconhece não ser essa a verdadeira função da reparação civil. Se as responsabilidades penal e administrativa preocupam-se em aplicar uma punição justa ao ofensor que sirva de desincentivo a futuras condutas, a responsabilidade civil preocupa-se em proteger a vítima, recompondo seu patrimônio ou oferecendo uma compensação pecuniária que amenize o dano moral

30 A expressão é citada por Rafael Peteffi da Silva (2009, p. 89), que relata: "A posição doutrinária dominante no direito francês concorda com a afirmação de René Savatier de que a utilização da perda de uma chance no terreno médico hospitalar é o paraíso do juiz indeciso, devendo ser totalmente rechaçada, pois representa um desvirtuamento da utilização dos princípios da causalidade civil e um risco para a certeza de todo o sistema". O autor ainda salienta que esse entendimento também pode ser encontrado na doutrina norte-americana: "[...] Paul Speaker leciona que, quando o dano final já ocorreu e o processo aleatório chegou até o seu final, a única postura cabível é perguntar qual a causa do dano final e não quantas chances foram perdidas. Vislumbrar o aumento de probabilidades de causar um dano como uma espécie de prejuízo autônomo somente faria sentido nos casos em que o dano final ainda não ocorreu" (SILVA, 2009, p. 148). 
sofrido ${ }^{31}$. Em outras palavras, uma indenização punitiva pode constituir outra figura, mas responsabilidade civil não é 32 .

\section{O caráter punitivo da responsabilidade civil do médico pela suposta perda da chance de cura é demonstrado em trecho emblemático de Rafael Peteffi da Silva (2009, p. 242):}

Em defesa da adoção da teoria da perda de uma chance na seara médica, tem-se como principal argumento o caráter pedagógico (deterrence) que deve desempenhar a responsabilidade civil, isto é, o dever de indenizar o dano causado deve desmotivar o agente, bem como toda a sociedade, de cometer novamente o mesmo ato ofensivo.

A não adoção da teoria da perda de uma chance permitiria que os profissionais da área da saúde tivessem pouco cuidado com pacientes terminais ou com poucas chances de vida. Esta situação é facilmente explicável, pois enorme seria a dificuldade de provar o nexo de causalidade certo e direto entre a falha médica ou hospitalar e a morte do paciente, já que este, muito provavelmente, morreria pela evolução endógena da doença, mesmo com uma conduta

31 Por todos, v. Maria Celina Bodin de Moraes (2003, p. 330): "Só haveria verdadeira punição se se perquirisse o dano causado (em oposição a dano sofrido), o que já não é condizente com os fundamentos do sistema da responsabilidade civil. Também não há espaço no ordenamento brasileiro para o caráter punitivo, porque tal juízo pode, talvez, coadunar-se com sistema normativo que tem por finalidade ético-político-jurídica tão somente a justiça retributiva. Nosso sistema, no entanto, a partir da Constituição de 1988, baseia-se na justiça distributiva, em obediência ao fundamento solidarista". A crítica ao caráter punitivo da responsabilidade civil (inclusive no caso médico) também pode ser encontrada na doutrina francesa; v., ilustrativamente, a obra de Penneau (1973, p. 203).

32 A função punitiva da responsabilidade civil esbarra também em um problema de legalidade, como assinala Maria Celina Bodin de Moraes (2003, p. 227): "Na verdade, a solução que se apresenta mais condizente com o instituto da pena privada, ou do caráter punitivo, na responsabilidade civil é normatizar as fattispecie merecedoras, do ponto de vista do legislador democrático, de aplicação de pena pecuniária. A questão é, evidentemente, de ordem filosófica e de ordem sociológica e, sucessivamente, de política legislativa, hipóteses para as quais serão sempre insuficientes as soluções (necessariamente) casuísticas da jurisprudência". Remata a autora: "[...] corre-se o risco de violar o multissecular princípio da legalidade, segundo o qual nullum crimem, nulla poena sine lege; além disso, em sede civil, não se colocam à disposição do ofensor as garantias substanciais e processuais - como, por exemplo, a maior acuidade quanto ao ônus da prova - tradicionalmente prescritas ao imputado no juízo criminal” (MORAES, 2003, p. 260). 
médica exemplar. Assim, a falha médica não se caracterizaria como uma condição necessária para o surgimento do dano.

O trecho ilustra bem a lógica que tem guiado a aplicação da teoria da perda de uma chance à responsabilidade civil do médico: o que se busca, em verdade, é responsabilizar o médico, mesmo se não houver falha em sua atuação, mesmo se tiver agido com uma conduta exemplar, sob a alegação de que isso preveniria o paciente contra uma possível tendência dos profissionais da medicina a tratá-los com descaso ou pouco cuidado ${ }^{33}$. Constrói-se, assim, um cenário que só pode levar o médico a adotar a chamada medicina defensiva ${ }^{34}$, buscando a viabilidade da manutenção de sua prática profissional em detrimento da oferta das melhores opções possíveis de tratamento para o paciente.

A aplicação da responsabilidade civil pela perda de uma chance à prática da medicina revela, ainda, não apenas o atual cenário de desconfiança em face do médico no direito brasileiro atual, como

33 Um fator relevante para esse desvio de perspectiva pode ser a importação de figuras conhecidas no direito estrangeiro, sem a consideração de que as lógicas desses sistemas podem (e costumam ser) diferentes. É o que ilustra o seguinte relato de Rafael Peteffi da Silva (2009, p. 186-187): “Da mesma forma que ocorria com a jurisprudência francesa, alguns magistrados norte-americanos também acreditam que as chances perdidas pelos pacientes possam constituir danos autônomos do dano final e, portanto, devem ser indenizados. Porém, o ordenamento norte-americano é o primeiro a admitir a reparação das chances perdidas com fundamento em um padrão alternativo de causalidade. Portanto, verifica-se a reparação das espécies de responsabilidade pela perda de uma chance na seara médica, independentemente da natureza jurídica que se possa atribuir às chances".

34 Na lição de Judith Martins-Costa (2005, p. 123): "A medicina defensiva pode ser definida como a prática médica que prioriza condutas e estratégias diagnóstico-terapêuticas que têm como objetivo evitar demandas judiciais. Implica um desvio da conduta considerada cientificamente padrão nos cuidados com o paciente por se caracterizar pelo uso excessivo de recursos técnicos. O benefício visado pela prática da medicina defensiva é, essencialmente, do próprio médico e subsidiariamente do paciente. [...] Mas pergunta-se: com base em que critérios o médico teria condições de avaliar o risco de ser processado? Será possível definir, de antemão, uma personalidade mais ou menos propensa a ingressar na Justiça? Esta regra não estaria gerando preconceito e desconfiança, estimulando a belicosidade entre usuários e prestadores dos serviços à saúde? Será possível formar uma aliança terapêutica eficaz isenta de confiança mútua? A situação requer, pois, prudência e razoabilidade, principalmente por parte dos médicos (que devem ter consciência que o paciente é prioritário) e dos juízes (que não podem tratar a prestação de serviços médicos como uma outra qualquer relação de consumo, devendo estar atentos para as especificidades da atividade médica)". 
também a confusão entre a necessidade de se proteger o paciente e uma suposta possibilidade de transformar essa proteção em um ônus econômico insuportável para o profissional ${ }^{35}$. Em posicionamento mais restritivo quanto à aplicabilidade da teoria nessa seara, Fernando Noronha sustenta que apenas se poderia falar de perda de uma chance de cura nos casos em que o médico comprovadamente tivesse faltado com a diligência esperada (agido, portanto, com culpa) e, além disso, não fosse possível identificar se o dano efetivamente sofrido pelo paciente era ou não decorrente da conduta médica, do natural desenvolvimento da enfermidade ou de ambos atuando conjuntamente.

Nesses casos, de fato, a questão torna-se exclusivamente de causalidade, pois para o autor, coerentemente com o que se sustenta neste trabalho, a identificação da conduta culposa por parte do profissional é pressuposto para a sua responsabilização ${ }^{36}$. A imputação do dever de indenizar ao médico, contudo, a despeito da certeza quanto ao liame de causalidade, é assim justificada:

Perante esse circunstancialismo, o fato de não existir prova suficiente que permita selecionar um dos dois fatores que são possível causa do dano verificado parece não ser justificativa para aplicar aqui a regra do 'tudo ou nada' e concluir que o lesado não poderá receber reparação nenhuma. Neste caso, essa regra seria profundamente injusta, o que é motivo suficiente para se duvidar do acerto de interpretações que conduzam a ela. Se é sabido que o dano foi causado por um de dois fatos, e que pode até ter

35 Para uma análise mais detida dessas tendências, permita-se remeter a Souza (2015, p. 76-80).

36 "Somente quando a causa do agravamento do estado do paciente não é conhecida e, além disso, quando houve uma terapêutica inadequada (ou se a terapêutica até foi adequada, mas oferecia risco, dos quais não se esclareceu o paciente [...]), é que surge a questão de saber se não poderá haver responsabilidade por chances perdidas. Nestes casos, mesmo que não se saiba qual foi a causa do dano, ele só pode ter acontecido em uma de duas situações: ou foi devido simultaneamente ao ato terapêutico inadequado e à evolução endógena da doença, ou resultou somente de um desses fatores, sem se saber qual" (NORONHA, 2010, p. 712). De se ressaltar que a falha no dever de informar pode ser inserida também no âmbito da culpa médica, não sendo obrigatória a distinção feita pelo autor. 
resultado da ação dos dois, não é razoável que o lesado fique sem reparação nenhuma. (NORONHA, 2010, p. 713).

Como se percebe, a solução proposta no trecho supracitado baseiase em um juízo de equidade que visa garantir que a vítima não restará irressarcida quando o liame de causalidade se encontra parcialmente demonstrado ${ }^{37}$. De fato, trata-se de uma solução que se aproxima muito do que se convencionou denominar causalidade alternativa ${ }^{38}$, a justificar, do ponto de vista da técnica jurídica, que o médico possa responder proporcionalmente à probabilidade de sua conduta culposa ter concorrido para o dano ${ }^{39}$. Nessa hipótese, porém, mais uma vez se questiona se seria o caso de recorrer à figura da perda de uma chance. Se, de fato, for possível concluir que em determinados casos a probabilidade de o médico ter contribuído para o dano efetivamente sofrido pela vítima é alta o suficiente para responsabilizá-lo, com todas as cautelas que se aplicam tradicionalmente à causalidade alternativa, restaria perguntar: não é pelo dano efetivamente sofrido pelo paciente que o profissional será, nesses termos, parcialmente responsabilizado?

Certamente seria possível alegar que a teoria da perda de uma chance, mesmo em sua vertente clássica (relacionada a não obtenção

37 Este papel de garantia à vítima já foi reconhecido na doutrina norte-americana; cumpre frisar, no entanto, que no sistema americano de responsabilidade civil predomina a regra do all or nothing, a exigir do paciente a demonstração de que a probabilidade de que a negligência médica tenha causado o dano seja superior a $50 \%$, sob pena de não receber qualquer indenização (a respeito, v. BUCKLER, 2009). No sistema brasileiro, a possibilidade de se reconhecer a concorrência da negligência profissional com outras causas concomitantes parece superar, com vantagens, semelhante rigidez, sem o necessário recurso à teoria da perda de uma chance.

38 Conforme consta da atualização da obra de Caio Mário da Silva Pereira (2011, p. 118), a causalidade alternativa insere-se no âmbito de uma "tendência a tornar flexível o nexo causal, situam-se as chamadas presunções de causalidade, a traduzir tanto a superação de obstáculos probatórios para a comprovação do nexo de causalidade, como a aplicação de juízos de probabilidade em sua definição. Nessa direção, alude-se à causalidade alternativa, aplicável a casos em que, diante da impossibilidade de se determinar quais agentes, dentre os diversos participantes do evento danoso, concorreram para o dano, este é imputado à conduta do grupo coletivamente considerado35. Uma vez demonstrado que a ação daquela coletividade resultou necessariamente no dano, atribui-se a todos os partícipes da atividade o dever de indenizar".

39 O próprio autor reconhece tratar-se de causalidade alternativa, concluindo: "a reparação deve corresponder à percentagem das chances com que o fato do responsável contribuiu para o dano final: esse será o valor da chance subtraída ao lesado" (NORONHA, 2010, p. 714). 
de um benefício), radica-se em uma tentativa de proteger a vítima e garantir que ela não fique irressarcida em hipóteses nas quais não poderia comprovar, com a razoabilidade e habitualidade necessárias, a existência de lucro cessante. Tal raciocínio, de todo procedente, tem o mérito de reconhecer uma escolha do intérprete revestida na forma da construção dogmática, e nada impede, em linha de princípio, sua aplicação à relação entre médico e paciente. Contudo, independentemente de se preferir a aplicação da teoria da perda de uma chance ou, como se sustentou no presente estudo, reconhecerse que, nos casos em que não se evitou o malefício, a simples análise de causalidade entre a conduta profissional e o dano concretamente sofrido é suficiente, importa frisar que a responsabilização pela perda da chance, em qualquer de suas modalidades, cria para aquele que arcará com a indenização um regime de responsabilidade agravada ${ }^{40}$.

Caso se considere que a particular posição de garantidor em que se coloca o profissional da medicina que se dispõe a tratar do paciente justifica esse agravamento em sua responsabilidade, restaria justificada a responsabilização do médico nessas hipóteses ${ }^{41}$-embora permaneça a conclusão de que o caso parece ser não propriamente

40 De fato, na perda de uma chance clássica, a afirmação de que a chance constitui bem jurídico autonomamente tutelável, por se considerar que integrava o patrimônio da vítima antes de ser perdida, corresponde a uma escolha do intérprete, que, na ponderação dos valores envolvidos, concluiu pela existência de dano ressarcível. No paradigma do dano injusto, não é a lesão à norma jurídica expressa que determina a existência de dano (como ocorria no ato ilícito), mas sim o juízo de merecimento de tutela realizado pelo julgador, no caso concreto, acerca do bem jurídico que a vítima alega ter sido vulnerado. Nessa perspectiva, justifica-se a afirmação de que, ao privilegiar a tutela ao interesse da vítima, restringiu-se a tutela ao interesse do ofensor de não responder por dano em que não houvesse certeza quanto à causalidade - e de que, portanto, sua responsabilidade foi agravada. Sobre a discussão, permita-se remeter a Souza (2012, p. 100 e ss).

$41 \quad$ A ideia de um particular dever de garantia parece ser a ótica que orientou precedente do Superior Tribunal de Justiça que qualificou como hipótese de perda de uma chance de cura um caso de recusa de atendimento: "RECURSO ESPECIAL. RESPONSABILIDADE CIVIL. VIOLAÇÃO DO ART. 535 DO CPC. INEXISTÊNCIA. SÚMULA N 7/STJ. NÃO INCIDÊNCIA. HOSPITAL PARTICULAR. RECUSA DE ATENDIMENTO. OMISSÃO. PERDA DE UMA CHANCE. DANOS MORAIS. CABIMENTO. [...] 4. Restando evidenciado que nossas leis estão refletindo e representando quais as prerrogativas que devem ser prioritariamente observadas, a recusa de atendimento médico, que privilegiou trâmites burocráticos em detrimento da saúde da menor, 
de indenização pela perda de uma chance, mas sim de causalidade alternativa na produção de um dano concreto, na medida em que se está diante da probabilidade de causalidade, ao passo que a teoria da perda de uma chance, em princípio, prevê a certeza quanto ao nexo causal. Semelhante agravamento não parece, contudo, encontrar subsídio positivo no ordenamento brasileiro, sobretudo quando se insiste em afirmar que o regime de responsabilidade do médico permanece ancorado no paradigma da culpa.

\section{Conclusão}

A teoria da perda de uma chance não parece, à luz de tais considerações, encontrar na responsabilidade civil do médico seu campo mais adequado de aplicação. Trata-se de figura excepcional, cuja verificação exige especial cautela por parte do julgador ${ }^{42}$. Ademais, a perda da chance apresenta-se muito mais consentânea com as suas hipóteses clássicas de aplicação, nas quais não se produziu um dano em concreto, e sim a perda de uma oportunidade de ganho ou benefício. A já complexa responsabilidade civil do médico dispensa, por seu turno, essa teoria, que pouco acrescenta à tutela do paciente (o

não tem respaldo legal ou moral. 5. A omissão adquire relevância jurídica e torna o omitente responsável quando este tem o dever jurídico de agir, de praticar um ato para impedir o resultado, como na hipótese, criando, assim, sua omissão, risco da ocorrência do resultado. 6 . A simples chance (de cura ou sobrevivência) passa a ser considerada como bem juridicamente protegido, pelo que sua privação indevida vem a ser considerada como passível de ser reparada [...]" (BRASIL. STJ. 1.335.622, 3 ${ }^{a}$ T. Rel. Min. Ricardo Villas Bôas Cueva, julg. 18.12.2012). Registrese, contudo, que, no caso concreto, a ação indenizatória foi proposta contra o hospital (e não contra o profissional individualmente), que se recusara a receber a paciente a despeito de ordem judicial - fatores que parecem justificar o agravamento da responsabilidade.

42 Afirma Anderson Schreiber (2013, p. 204): “[...] a distinção entre lucro cessante, perda da chance e dano hipotético acaba por assentar mais no grau de probabilidade do resultado final que propriamente em uma diferença ontológica ou conceitual. E esse grau de probabilidade oscila conforme fatores variados, alguns extremamente peculiares e individuais, próprios, como se viu, da situação concreta vivida pela vítima. Tal constatação evidencia a importância da atuação do Poder Judiciário na adequada qualificação das perdas sofridas, especialmente por meio de parâmetros para o julgamento de casos futuros, em um continuado aprimoramento da perícia judicial em torno da perda da chance". 
qual poderá invocar o dano concretamente produzido como fundamento da pretensão indenizatória) e põe em risco a adequada investigação da conduta culposa do profissional, indispensável à sua responsabilização.

\section{REFERÊNCIAS}

AGUIAR JÚNIOR, Ruy Rosado de. Responsabilidade civil do médico. In: TEIXEIRA, Sálvio de Figueiredo (Coord.). Direito \& medicina: aspectos jurídicos da medicina. Belo Horizonte: Del Rey, 2000. p. 133-180.

BENACCHIO, Marcelo. Responsabilidade civil do médico: algumas reflexões. In: NERY, Rosa Maria de Andrade; DONINNI, Rogério (Coord.). Responsabilidade civil: estudos em homenagem ao Professor Rui Geraldo Camargo Viana. São Paulo: Revista dos Tribunais, 2009. p. 320-349.

BODIN DE MORAES, Maria Celina. Danos à pessoa humana: uma leitura civil-constitucional dos danos morais. Rio de Janeiro: Renovar, 2003.

BUCKLER, Stephanie. Medical Malpractice Law-Loss of Chance: Recovery for the Lost Opportunity of Survival-Matsuyama v. Birnbaum, 890 N.E.2d 819 (Mass. 2008). Journal of Health \& Biomedical Law, Bonston, v. V, p. 117-129, 2009.

CAVALIERI FILHO, Sergio. Programa de direito do consumidor. São Paulo: Atlas, 2005.

GIOSTRI, Hildegard Taggesell. Erro médico à luz da jurisprudência comentada. Curitiba: Juruá, 2005.

KONDER, Carlos Nelson; DALSENTER, Thamis. Questões atuais da responsabilidade civil médica e hospitalar. In: TEIXEIRA, Ana Carolina Brochado; DADALTO, Luciana. Dos hospitais aos tribunais. Belo Horizonte: Del Rey, 2013. p. 463-497.

MARTINS-COSTA, Judith. Entendendo problemas médico-jurídicos em ginecologia e obstetrícia. Revista dos Tribunais, São Paulo, v. 831, p. 106-127, jan. 2005. 
NORONHA, Fernando. Direito das obrigações: fundamentos do direito das obrigações; introdução à responsabilidade civil. São Paulo: Saraiva, 2010.

PENNEAU, Jean. Faute et erreur en matière de responsabilité medicale. Paris: Librairie Générale de Droit et de Jurisprudence, 1973.

PEREIRA, Caio Mário da Silva. Responsabilidade civil. 10. ed. atual. Rio de Janeiro: GZ, 2011.

RODOTÀ, Stefano. II problema della responsabilità civile. Milano: Giuffrè, 1967.

SAVI, Sérgio. Responsabilidade civil por perda de uma chance. São Paulo: Atlas, 2006.

SCHREIBER, Anderson. Direito civil e constituição: a perda de uma chance na jurisprudência do Superior Tribunal de Justiça. São Paulo: Atlas, 2013.

SILVA, Rafael Peteffi da. Responsabilidade civil pela perda de uma chance. São Paulo: Atlas, 2009.

SOUZA, Eduardo Nunes de Souza. Do erro à culpa na responsabilidade civil do médico: estudo na perspectiva civil-constitucional. Rio de Janeiro: Renovar, 2015.

. Merecimento de tutela: a nova fronteira da legalidade no direito civil. Revista de Direito Privado, São Paulo, v. 58, p. 75-107, abr.-jun. 2014.

TEPEDINO, Gustavo. Nexo de causalidade: conceito, teoria e aplicação na jurisprudência brasileira. In: RODRIGUES JUNIOR, Otavio Luiz; MAMEDE, Gladston; ROCHA, Maria Vital da (Coord.). Responsabilidade civil contemporânea: em homenagem a Silvio de Salvo Venosa. São Paulo: Atlas, 2011. p. 106-119.

Recebido em: 09/11/2015

Aprovado em: 10/11/2015 